\title{
Penerapan Sistem Pengendalian Internal pada PD Citra Kartini Bandar Lampung
}

\author{
Fitri Agustina \\ fitriagustina86@gmail.com \\ Program Studi Akuntansi \\ Institut Informatika dan Bisnis Darmajaya, Bandar Lampung, Indonesia
}

\section{Intisari}

Penelitian ini merupakan penelitian deskriptif dengan studi kasus yang dilakukan pada Perusahaan Dagang (PD) Citra Kartini Lampung. Adapun tujuan dari penelitian ini adalah untuk melakukan perbaikan sejauh mana penerapan sistem pengendalian internal yang baik sesuai dengan karakteristik serta kompleksitas perusahaan dagang yang mengacu pada standar Committee of Sponsoring Organizations of The Treadway Commission (COSO) yang diterapkan pada Perusahaan Dagang (PD) Citra Kartini Lampung. Penelitian ini menggunakan metode wawancara dan koesioner kepada pimpinan selaku dewan pengawas dan manajer operasional selaku kepala divisi dan staf. Dari hasil analisis dapat disimpulkan bahwa PD Citra kartini belum menerapkan sistem pengendalian internal. Hal tersebut tercermin dari belum adanya prosedur dan sistem yang baik.

Kata kunci: Sistem Pengendalian Internal, COSO 


\title{
Implementation of Internal Control System at PD Citra Kartini, Bandar Lampung \\ Fitri Agustina \\ fitriagustina86@gmail.com \\ Program Studi Akuntansi \\ Institut Informatika dan Bisnis Darmajaya, Bandar Lampung, Indonesia
}

\begin{abstract}
This research is a descriptive research with case study conducted at Perusahaan Dagang (PD) Citra Kartini Lampung. The purpose of this study is to improve the extent to which the application of good internal control system in accordance with the characteristics and complexity of trading companies that refer to the Committee of Sponsoring Organizations of The Treadway Commission (COSO) standard applied to PD Citra Kartini Lampung. This research uses interview and questioner method to the leader as supervisory board and operational manager as division head and staff. From the result it can be concluded that PD Citra Kartini still does not apply internal control system. This is reflected in the absence of good procedures and system.
\end{abstract}

Key Words: Internal Control System, COSO 


\section{JAAF (Journal of Applied Accounting and Finance) \\ Volume 2, Number 1, 2018, 85-98}

\section{LATAR BELAKANG}

Sistem Pengendalian Internal (SPI) tidak hanya diterapkan pada perusahaan besar, tetapi juga bisa diterapkan pada perusahaan berskala kecil dan menengah (Hartadi, 1999). Banyak orang beranggapan bahwa SPI diterapkan pada prinsipnya untuk memisahkan wewenang dan serta pembagian tugas bagi para karyawan perusahaan, sehingga tidak dapat diterapkan pada perusahaan kecil yang tentunya memiliki jumlah karyawan terbatas.

Dalam perusahaan perseorangan, pemilik berhubungan langsung dengan semua pengendalian baik penghasilan, biaya dan perlindungan terhadap kerugian- kerugian. Pemilik dipandang mampu apabila dia dapat menjaga dan mengawasi otorisasi, penyelenggaraan catatan, fungsi penyimpanan dan menjamin ketelitian pengolahan data secara memuaskan baik untuk kepentingannya maupun akuntan publik (Swastha, 2007).

Perusahaan Dagang (PD) Citra Kartini merupakan perusahaan keluarga yang mempunyai tujuan mendapatkan laba, dimana kelangsungan usahanya ditentukan oleh seberapa besar laba yang diperoleh dengan cara menjual produk. Produk-produk yang dijual berupa meja, kursi, lemari, tempat tidur, kitchen set dan keperluan rumah tangga lain yang terbuat dari kayu jati Jepara. PD Citra Kartini merupakan perusahaan yang sedang berkembang dan memiliki cabang di Bandar Lampung.

Dalam menjalankan operasionalnya, perusahaan memiliki berbagai permasalahan. Penulis melihat bahwa PD Citra Kartini belum menerapkan sistem pengendalian internal, hal tersebut dapat dilihat dari penerapan prosedur sistem informasi akuntansi manual atau seadanya, serta tidak adanya struktur organisasi, job description dan prosedur tertulis. Akibatnya terjadi perangkapan jabatan, tumpang tindih tugas, dan tanggung jawab. Selain itu sistem akuntansi PD Citra Kartini tidak memiliki pencatatan atas transaksi-transaksi yang terjadi, tidak menggunakan kartu hutang dan piutang, serta buku besar. Akibatnya informasi yang berguna untuk perusahaan minim. Menurut (Romney, 1997) minimnya informasi mengakibatkan keputusan yang salah karena tanpa didasari oleh informasi yang lengkap dan akurat. Berdasarkan uraian diatas, penulis tertarik untuk melakukan penelitian mengenai Sistem Pengendalian Internal di perusahaan dagang skala menengah dengan judul penelitian: " Penerapan Sistem Pengendalian Internal pada PD Citra Kartini".

Penelitian ini nantinya akan memberikan kontribusi kepada PD Citra Kartini mengenai bagaimana penerapan sistem pengendalian internal yang baik sesuai dengan karakteristik serta kompleksitas perusahaan dagang. Dalam melakukan penelitian penulis berpedoman pada komponen pengendalian internal COSO (The Committee of Sponsoring Organization's of the Treadway Commision). Komponen pengendalian internal yang penulis gunakan terdiri dari: (1) Lingkungan pengendalian, (2) Penilaian resiko, (3) Aktivitas pengendalian, (4) Informasi dan komunikasi serta (5) Pengawasan.

\section{LANDASAN TEORI}

\section{Sistem Pengendalian Internal}

Menurut Hartadi (1999) sistem pengendalian internal dapat mempunyai beberapa pengertian yaitu sistem pengendalian internal dalam arti sempit dan dalam arti luas. AICPA (American Institute of Certified Public Accountants, 1992) memberi definisi sistem pengendalian internal meliputi struktur organisasi, semua metode dan ketentuan-ketentuan yang terkoordinasi yang dianut dalam perusahaan untuk melindungi harta kekayaan, memeriksa ketelitian, dan seberapa jauh data akuntansi dapat dipercaya, meningkatkan efisisiensi usaha dan mendorong ditaatinya kebijakan perusahaan yang telah ditetapkan. 
Pengendalian internal merupakan suatu proses yang dijalankan oleh dewan komisaris, manajemen, dan personil lain didalam entitas, yang didesain untuk memberikan keyakinan memadai tentang pencapaian tiga tujuan utama yaitu (a) keandalan laporan keuangan, (b) efektivitas dan efisiensi operasi, dan (c) kepatuhan terhadap hukum dan peraturan yang berlaku. (The Committee of Sponsoring Organization's of the Treadway Commision, 1992). Pengendalian internal setiap entitas memiliki keterbatasan bawaan (Mulyadi, 2001). Pengendalian internal hanya memberikan keyakinan memadai bukan mutlak kepada manajemen dan komisaris tentang pencapaian tujuan entitas. Berikut ini adalah keterbatasan bawaan yang melekat dalam setiap pengendalian internal:

1. Kesalahan dalam pertimbangan

Manajemen dan personel lain bisa salah dalam mempertimbangkan keputusan bisnis yang diambil atau dalam melaksanakan tugas rutin, karena tidak memadainya informasi, keterbatasan waktu, atau tekanan lain.

2. Gangguan

Gangguan dalam pengendalian yang telah ditetapkan dapat terjadi karena personil secara keliru memahami perintah atau membuat kesalahan karena kelalaian, tidak adanya perhatian, atau kelelahan. Perubahan ini bersifat sementara atau permanen dalam personil atau dalam sistem dan prosedur dapat pula mengakibatkan gangguan.

3. Kolusi

Tindakan bersama beberapa individu untuk tujuan kejahatan disebut dengan kolusi. Kolusi dapat mengakibatkan bobolnya pengendalian internal yang dibangun untuk melindungi kekayaan entitas dan tidak terungkapkan ketidakberesan atau tidak terdeteksinya kecurangan oleh pengendalian internal yang dirancang.

4. Pengabaian oleh manajemen

Manajemen dapat mengabaikan kebijakan atau prosedur yang telah ditetapkan untuk tujuan yang tidak sah seperti keuntungan pribadi manajer, penyajian kondisi keuangan yang berlebihan, atau kepatuhan semu.

5. Biaya lawan manfaat (cost versus benefit)

Biaya yang diperlukan untuk mengoperasikan pengendalian internal tidak boleh melebihi manfaat yang diharapkan dari pengendalian internal tersebut. Karena pengukuran secara tepat baik biaya maupun manfaat biasanya tidak mungkin dilakukan, manajemen harus memperkirakan dan mempertimbangkan secara kuantitatif dan kualitatif dalam mengevaluasi biaya dan manfaat suatu pengendalian internal.

Setiap orang dalam organisasi bertanggung jawab terhadap, dan menjadi bagian dari pengendalian internal organisasi. Pihak-pihak yang bertanggung jawab terhadap pengendalian internal diantaranya manajemen, dewan komisaris, auditor internal, personil entitas dan auditor independen.

\section{Sistem Pengendalian Internal pada perusahaan kecil dan Menengah}

Menurut Newman dalam Hartadi (1999) prinsip pengendalian internal terutama didasarkan atas pembagian tugas dan pemisahan wewenang antara para pegawai. Maka sering orang mengira bahwa prinsip tersebut tidak dapat diterapkan dalam suatu perusahaan kecil yang mempunyai jumlah pegawai terbatas, pandangan yang salah ini disebabkan karena orang melupakan banyak prinsip-prinsip pengendalian internal bekerja secara otomatis dan ikut sertanya pemilik perusahaan sendiri akan banyak membantu efektivitas sistem pengendalian internal. Dalam perusahaan kecil, manajemen atau pemilik berhubungan langsung dengan semua pengendalian baik penghasilan, biaya dan perlindungan terhadap kerugian-kerugian. Untuk itu dia harus menentukan ukuran-ukuran penting untuk mencapai tujuan pengendalian internal dan perlindungan aktiva. Manajemen 


\section{JAAF (Journal of Applied Accounting and Finance) \\ Volume 2, Number 1, 2018, 85-98}

atau pemilik dipandang mampu apabila dia dapat menjaga dan mengawasi otorisasi, penyelenggaraan catatan, fungsi penyimpanan dan menjamin ketelitian pengolahan data secara memuaskan baik untuk kepentingannya maupun akuntan publik. Maka harus diadakan pemeriksaan yang teliti terhadap rekening-rekening, jurnal-jurnal, dan dokumen pendukung (Nuritomo, 2010).

\section{METODE PENELITIAN}

Penelitian ini adalah penelitian deskriptif dengan studi kasus. Penelitian deskriptif adalah suatu penelitian yang bertujuan untuk menggambarkan dan mengungkapkan suatu keadaan, masalah, peristiwa yang sesungguhnya pada saat penelitian dilakukan (Cooper, 2006). Hasil penelitian hanya untuk memberi gambaran tentang keadaan yang sebenarnya mengenai objek yang diteliti. Pelaksanaan dan hasil penelitian ini meliputi pengumpulan data, penyusunan data, analisis data. Yin (2000) mengatakan bahwa studi kasus berarti penelitian dengan karakteristik masalah yang berkaitan dengan kondisi saat ini dari subyek yang diteliti. Tujuan dari studi ini adalah melakukan penyelidikan mengenai subyek tertentu untuk memberikan gambaran yang lengkap mengenai subyek tersebut.

Subyek Penelitian ini adalah PD Citra Kartini yang beralamat di Bandar Lampung. Penelitian ini bertujuan untuk memberikan rekomendasi penerapan Sistem Pengendalian Internal kepada PD Citra Kartini dengan cara menganalisis permasalahan yang ada, lalu mencari solusi alternatif pemecahan berdasarkan teori-teori yang ada.

\section{Jenis dan Sumber Data}

Jenis data yang digunakan adalah data kualitatif. Data kualitatif adalah data yang tidak dapat dikuantifikasi atau tidak dapat diukur (Hadi, 2006). Data kualitatif yang digunakan dapat berupa gambaran umum perusahaan, struktur organisasi, job description, data mengenai prosedur akuntansi dan lain-lain. Sumber data yang digunakan adalah data primer. Data primer merupakan sumber data penelitian yang diperoleh secara langsung dari sumber asli yang diperoleh penulis melalui wawancara dan kuisioner kepada pihak terkait

\section{Teknik Pengumpulan Data}

Adapaun teknik yang digunakan dalam penelitian lapangan ini adalah menggunakan teknik: Wawancara dan Daftar pertanyaan (kuesioner). Penelitian mengenai Penerapan Sistem Pengendalian Internal yang penulis lakukan mengacu pada Sistem Pengendalian Internal COSO (The Committee of Sponsoring Organization's of the Treadway Commision), sehingga pembuatan kuisioner berdasar pada isi lima komponen COSO tersebut. Penelitian dilakukan dengan melihat kenyataan yang ada di lapangan lalu memberikan rekomendasi berdasarkan teori yang ada. Kuisioner dan wawancara ditujukan kepada pimpinan selaku dewan pengawas, manajer operasional selaku kepala divisi dan tiga orang staf yang merupakan sampel dari tiap divisi. Penelitian ini dilakukan pada Juni 2017.

\section{HASIL DAN PEMBAHASAN Deskripsi Perusahaan}

PD Citra Kartini adalah sebuah perusahaan dagang furniture, yang didirikan pada tahun 1972 di Tasikmalaya Jawa Barat. Perusahaan perseorangan ini dipimpin oleh pemilik perusahaan sendiri dan memilih usaha perdagangan furniture karena kota kelahirannya Jepara banyak menghasilkan kayu jati yang belum banyak diolah pada waktu 
itu. Pemilik tersebut memilih untuk membuka usahanya di Tasikmalaya Jawa Barat karena melihat potensi pasar yang lebih baik.

Tahun 1982 terjadi bencana alam besar di Tasikmalaya yaitu meletusnya Gunung Galunggung, dengan berbagai pertimbangan dan hasil penelitian ke beberapa kota akhirnya pemilik memutuskan untuk memindahkan usahanya ke Kota Bandar Lampung sampai dengan sekarang. Lokasi tersebut merupakan kantor, gudang sekaligus showroom tempat barang-barang furniture dipamerkan.

\section{Statistik Deskriptif}

Tabel 1. Deskripsi Responden

\begin{tabular}{|c|c|c|c|}
\hline \multicolumn{2}{|c|}{ Identitas Responden } & Jumlah & Persentase \\
\hline \multirow{3}{*}{ Jenis kelamin } & Laki-laki & 4 & $80 \%$ \\
\hline & Wanita & 1 & $20 \%$ \\
\hline & Jumlah & 5 & $100 \%$ \\
\hline \multirow{4}{*}{ Tingkat Pendidikan } & SMA & 3 & $60 \%$ \\
\hline & D3 & 1 & $20 \%$ \\
\hline & S1 & 1 & $20 \%$ \\
\hline & Jumlah & 5 & $100 \%$ \\
\hline \multirow{5}{*}{ Lama bekerja } & $\leq 2$ tahun & - & - \\
\hline & $2-5$ tahun & 2 & $40 \%$ \\
\hline & $6-10$ tahun & - & - \\
\hline & $11 \geq$ tahun & 3 & $60 \%$ \\
\hline & Jumlah & 5 & $100 \%$ \\
\hline
\end{tabular}

Sumber: Data diolah (2017)

Tabel 2. Statistik Deskriptif SPI PD Citra Kartini

\begin{tabular}{lccc}
\hline PERTANYAAN & \multicolumn{2}{c}{ JAWABAN } & Total (\%) \\
\cline { 2 - 3 } & Y (\%) & T(\%) & \\
\hline Lingkungan pengendalian & 60,5 & 39,5 & 100 \\
Penilaian resiko & 50 & 50 & 100 \\
Aktivitas pengendalian & 43,5 & 56,5 & 100 \\
Informasi dan komunikasi & 35,7 & 64,3 & 100 \\
Pengawasan & 91 & 9 & 100 \\
\hline
\end{tabular}

Sumber: Data diolah (2017)

\section{Hasil dan Pembahasan}

Berdasarkan hasil kuisioner dan wawancara didapatkan informasi bahwa;

1. Pimpinan sudah menetapkan standar perilaku dan etika. Pimpinan menerapkan sistem kekeluargaan pada semua karyawan hal tersebut dapat terlihat dari adanya pertemuan rutin antara pimpinan dan karyawan untuk membahas permasalahan dan kendala yang berkaitan dengan pekerjaan, etika, dan tata tertib yang harus dipatuhi. Sehingga pimpinan dapat mensosialisasikan dan mengingatkan pentingnya integritas dalam bekerja.

2. Pimpinan sudah memberikan pelatihan bagi karyawan khususnya karyawan yang akan ditempatkan dibagian produksi. Pimpinan turun langsung untuk melakukan pengawasan dan memberikan bimbingan serta pengarahan kepada karyawan. 


\section{JAAF (Journal of Applied Accounting and Finance) \\ Volume 2, Number 1, 2018, 85-98}

Karyawan yang memiliki kinerja baik nantinya akan berpengaruh atas upah yang akan diberikan (Moekiat, 1998), akan tetapi perusahaan belum mempekerjakan karyawan yang memiliki latar belakang pendidikan akuntansi untuk melakukan pencatatan laporan keuangan perusahaan.

3. Pengawasan dilakukan oleh pimpinan sendiri, sehingga pimpinan mengetahui keadaan perusahaan sebenarnya dan dapat menentukan keputusan dengan cepat apabila terdapat permasalahan dalam perusahaan. Pengawasan ditujukan kepada karyawan, produk yang dihasilkan serta peralatan operasional.

4. PD Citra Kartini belum memiliki visi dan misi perusahaan. Dalam sebuah organisasi visi dan misi merupakan hal yang penting (Thompson, Arthur, \& Strickland, 2001), agar pembuat keputusan lebih terarah tidak didominasi oleh manajemen karena manajemen banyak terkait dengan operasional perusahaan. Resiko bisnis dipertimbangkan cukup hati-hati tetapi penuh spekulasi.

5. PD Citra Kartini belum mempunyai struktur organisasi tertulis, bahkan struktur organisasi yang ada saat ini belum cukup sesuai dengan kompleksitas organisasi.

6. Perusahaan belum memiliki job description tertulis. Setiap karyawan mengetahui tugasnya berdasarkan penugasan yang diberikan pimpinan setiap pagi sebelum jam kerja dimulai. Tidak adanya job description menimbulkan perangkapan jabatan serta tumpang tindih tugas dalam operasional perusahaan.

7. Pimpinan sudah memberikan pelatihan bagi setiap karyawan, selain itu juga jika karyawan memiliki kinerja yang baik maka karyawan tersebut akan mendapatkan penghargaan dari perusahaan berupa kenaikan upah. Tunjangan yang diberikan berupa tunjangan keluarga, kesehatan serta keselamatan kerja, tetapi jika karyawan melakukan kesalahan maka manajemen akan memberikan sanksi berupa teguran, hingga pemecatan jika karyawan tersebut melakukan kesalahan fatal yang dapat merugikan perusahaan.

8. PD Citra Kartini memiliki beberapa resiko yang sampai saat ini belum bisa dikelola seperti perusahaan belum menggunakan dokumen, serta formulir dalam setiap kegiatan operasional peusahaan, belum melakukan pencatatan laporan keuangan yang baik, semua transaksi dicatat secara sederhana dan struktur organisasi yang ada saat ini belum cukup sesuai dengan ukuran dan kompleksitas perusahaan, masih terdapat tumpang tindih.

9. PD Citra Kartini masih belum memiliki system/prosedur akuntansi. Laporan keuangan dicatat secara sederhana akibatnya informasi yang berguna untuk perusahaan minim, sehingga keputusan yang diambil tanpa didasari oleh informasi yang lengkap dan akurat.

10. Perusahaan belum memiliki staf yang khusus melakukan pengawasan. Pengawasan diakukan oleh pimpinan sendiri. Pengawasan ditujukan kepada karyawan, produk yang dihasilkan serta peralatan operasional. Jika pimpinan sedang tidak ada maka pengawasan akan melemah.

\section{KESIMPULAN DAN SARAN}

Dari hasil analisis data yang penulis lakukan, didapat bahwa PD Citra kartini belum menerapkan sistem pengendalian internal. Hal tersebut terlihat dari belum adanya prosedur dan sistem akuntansi, belum melakukan pencatatan laporan keuangan, Struktur organisasi belum cukup sesuai dengan ukuran dan kompleksitas perusahaan.

Dari hasil penelitian dan pembahasan dilapangan penulis mempunyai beberapa saran kepada PD Citra Kartini, yaitu Perusahaan sebaiknya memiliki Visi dan Misi, Perusahaan 
sebaiknya memiliki SOP (Standar Operasional Prosedur), PD citra Kartini sebaiknya melakukan pencatatan laporan keuangan dan sistem informasi serta prosedur, PD Citra Kartini sebaiknya melakukan reshuffle struktur organisasi, Memiliki staf pengawas yang berdiri sendiri dan PD Citra Kartini sebaiknya membuat job description tertulis.

\section{REFERENSI}

Baridwan, Zaki. 1991 . Sistem Akuntansi Penyusunan Prosedur dan Metode Edisi ke-5. BPFE: Yogyakarta.

Cooper, Donald R. 2006. Metode Riset Bisnis Edisi ke-9. New York: Mc Graw Hill Companies Inc.

Hadyanto, Sabri. 2009. Evaluasi Pengendalian Internal Pada PT. Bank Rakyat Indonesia (Persero) Tbk Cabang Kendari. Tesis; Fakultas Ekonomika dan Bisnis, universitas Gadjah Mada, Yogyakarta..

Hartadi, Bambang. 1990. Sistem Pengendalian Internal Dalam Hubungannya Dengan Manajemen dan Audit. Edisi ke-3, BPFE: Yogyakarta

Moekiat. 1998. Analisis Jabatan. Bandung: Mandar Maju.

Mulyadi. 2002. Auditing Edisi ke-6. Jakarta: Salemba Empat

Mulyadi. 2001. Sistem Akuntansi Edisi ke-3. Jakarta:Salemba Empat.

Nuritomo. 2010. Evaluasi Struktur Pengendalian Internal Pada PT. Sumber Jaya. Tesis; Fakultas Ekonomika dan Bisnis, universitas Gadjah Mada, Yogyakarta.

Romney, Marshall B. 1997. Accounting Information System, $7^{\text {th }}$ edition. New York: Addison Wesley Logman Inc.

Swastha, Ibnu S. 2007. Pengantar Bisnis Modern. Yogyakarta: Liberty Offset.

Thompson, Jr. Arthur, and A.J Strickland III. 2001. Crafting and Executing Strategy. McGrawhill.

Hadi, Syamsul. 2006. Metodologi Penelitian Kuantitatif untuk Akuntansi dan Keuangan. Yogyakarta: Ekonisia.

Yin, Robert K. 2009. Studi Kasus Desain dan Metode. Jakarta: Rajawali Pers. 


\section{JAAF (Journal of Applied Accounting and Finance) \\ Volume 2, Number 1, 2018, 85-98}

\section{LAMPIRAN}

\section{Koesioner Penelitian}

Nama

Jenis kelamin

Umur

Jabatan

Lama bekerja

tahun

Pendidikan terakhir

Tanggal pengisian

Data di atas digunakan semata-mata untuk keperluan penelitian, mohon bapak/ ibu responden melengkapi data tersebut sesuai dengan keadaan sebenarnya.

\section{LINGKUNGAN PENGENDALIAN}

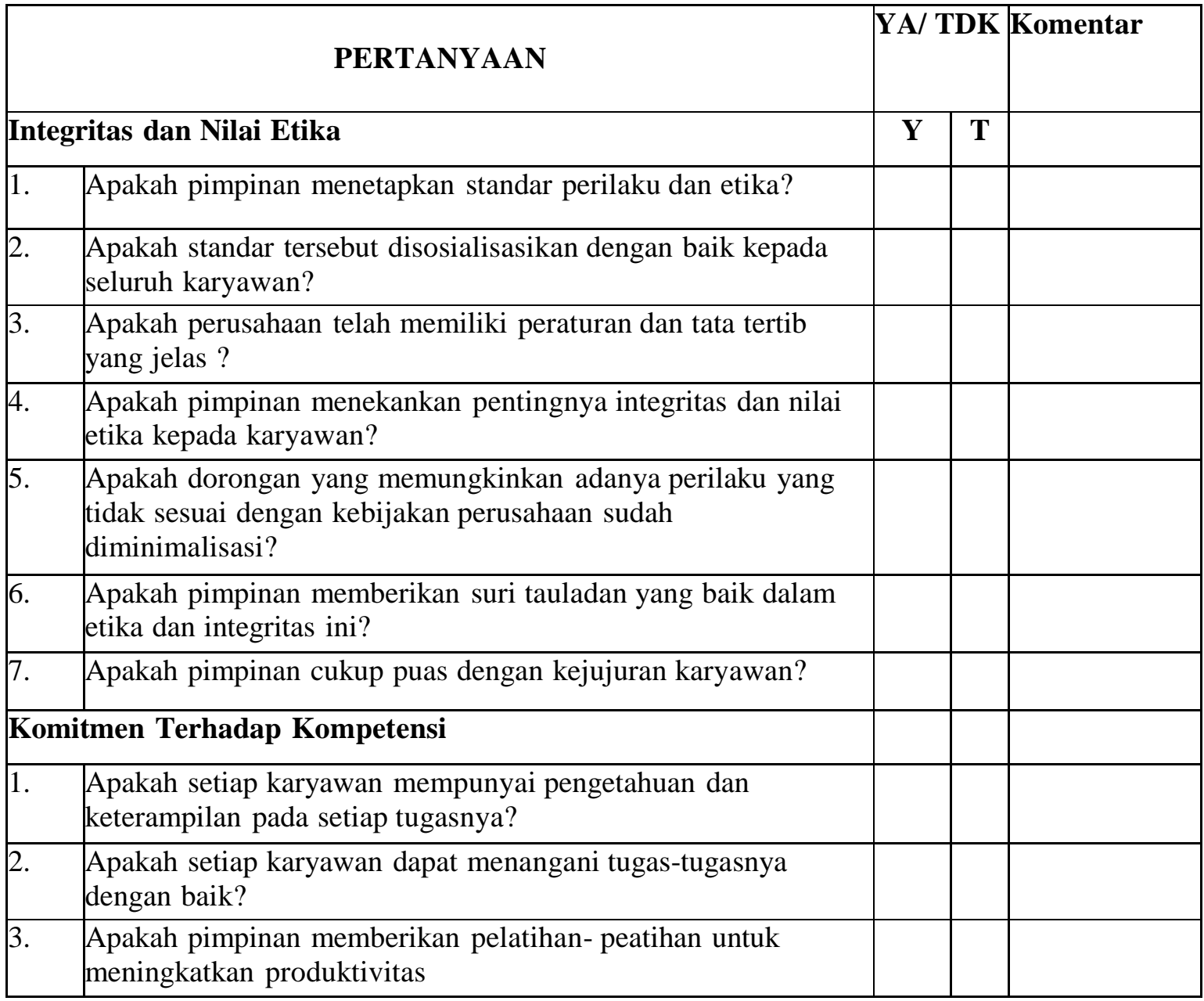

\begin{tabular}{|l|l|l|l|}
\hline 4. & $\begin{array}{l}\text { Apakah pimpinan melakukan penilaian terhadap prestasi dan } \\
\text { memberikan penghargaan kepada karyawan yang berprestasi } \\
\text { dan berpengalaman? }\end{array}$ & & \\
\hline 5. & $\begin{array}{l}\text { Apakah pimpinan turun langsung untuk melakukan pengawasan } \\
\text { dan memberikan bimbingan serta pengarahan kepada } \\
\text { karyawan? }\end{array}$ & & \\
\hline
\end{tabular}




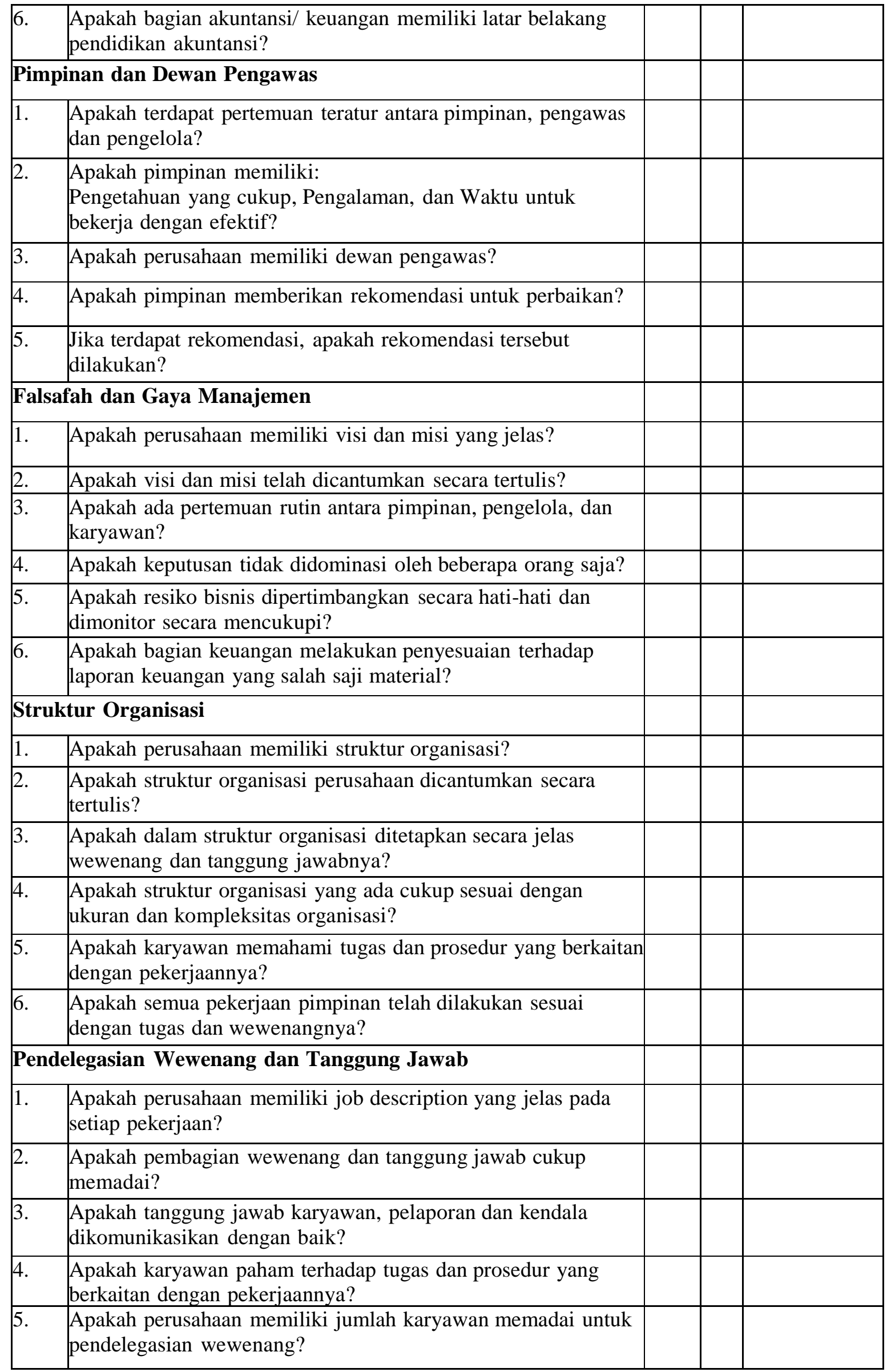




\section{JAAF (Journal of Applied Accounting and Finance) \\ Volume 2, Number 1, 2018, 85-98}

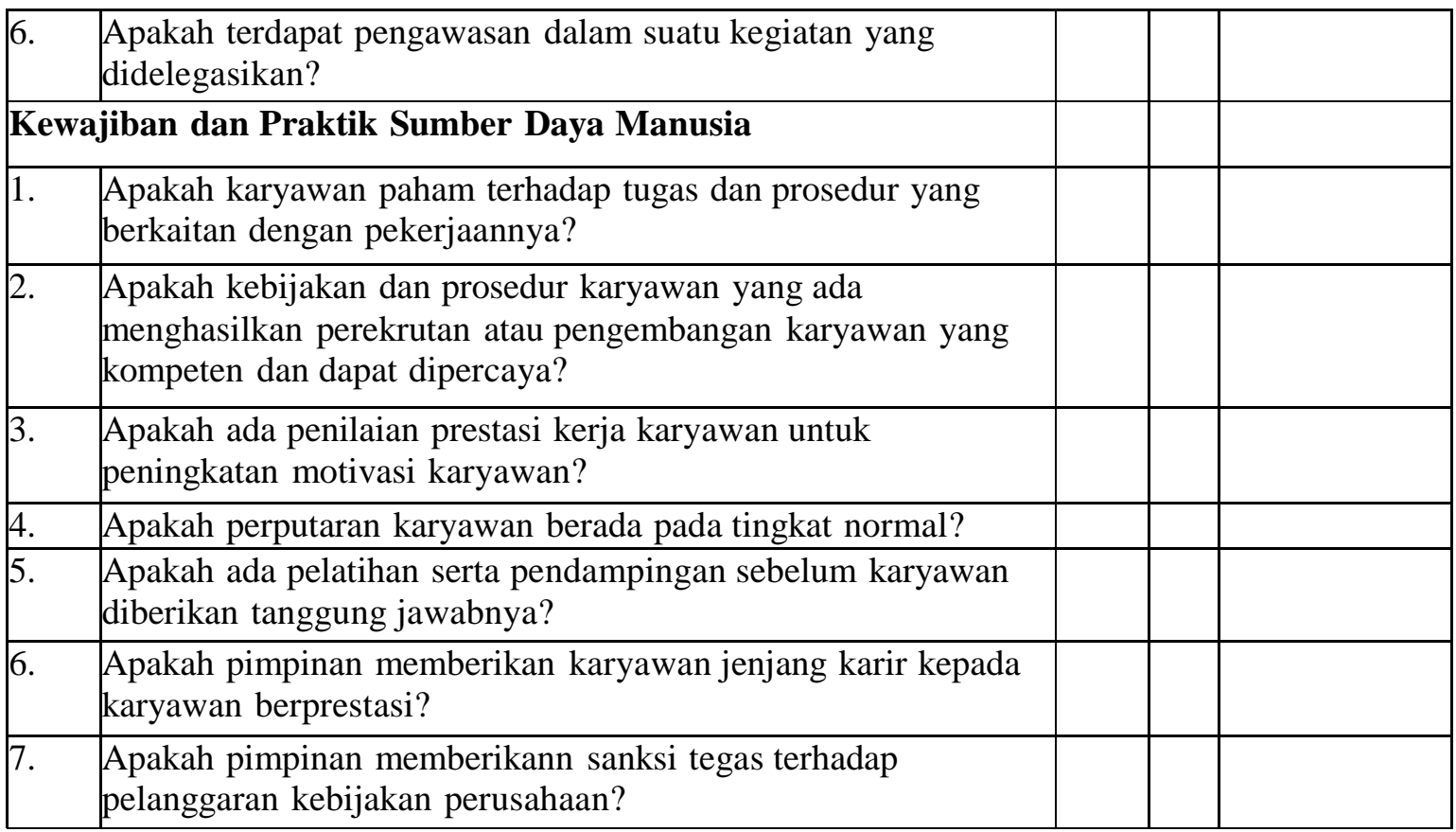

\section{PENILAIAN RESIKO}

\begin{tabular}{|c|c|c|c|c|}
\hline \multirow{2}{*}{\multicolumn{2}{|c|}{ PERTANYAAN }} & \multicolumn{3}{|c|}{ YA/ TDK Komentar } \\
\hline & & $\mathbf{Y}$ & $\mathbf{T}$ & \\
\hline & $\begin{array}{l}\text { Apakah perusahaan sudah menetapkan standar keselamatan } \\
\text { kerja karyawan? }\end{array}$ & & & \\
\hline 2. & $\begin{array}{l}\text { Apakah perusahaan sudah mengamankan persediaan bahan } \\
\text { baku di tempat yang aman agar terhindar dari kebakaran? }\end{array}$ & & & \\
\hline 3. & $\begin{array}{l}\text { Apakah persediaan bahan baku dan barang jadi sudah } \\
\text { diamankan dengan memadai dari kerusakan dan pencurian? }\end{array}$ & & & \\
\hline 4. & $\begin{array}{l}\text { Apakah perusahaan selalu mengecek harga bahan baku dan } \\
\text { barang furniture di pasaran? }\end{array}$ & & & \\
\hline 5. & $\begin{array}{l}\text { Apakah perusahaan selalu meng-update model furniture yang } \\
\text { dijual? }\end{array}$ & & & \\
\hline 6. & $\begin{array}{l}\text { Apakah perusahaan sudah mengantisipasi jika terjadi } \\
\text { pemadaman listrik yang menyebabkan karyawan menganggur? }\end{array}$ & & & \\
\hline 7. & $\begin{array}{l}\text { Apakah perusahan mendapatkan alternatif lain untuk } \\
\text { mengeringkan cat ketika cuaca tidak mendukung? }\end{array}$ & & & \\
\hline & $\begin{array}{l}\text { Apakah ada solusi jika perusahaan mengalami penurunan } \\
\text { penjualan? }\end{array}$ & & & \\
\hline 9 & $\begin{array}{l}\text { Apakah perusahaan sudah mengantisipasi jika terjadi penjualan } \\
\text { dengan kredit yang buruk? }\end{array}$ & & & \\
\hline 10 & $\begin{array}{l}\text { Apakah perusahaan memiliki prosedur pengiriman barang untuk } \\
\text { mengindari kesalahan pengiriman? }\end{array}$ & & & \\
\hline 11 & $\begin{array}{l}\text { Apakah perusahaan dapat mengatasi pengiriman barang yang } \\
\text { tidak dipesan dari vendor? }\end{array}$ & & & \\
\hline
\end{tabular}




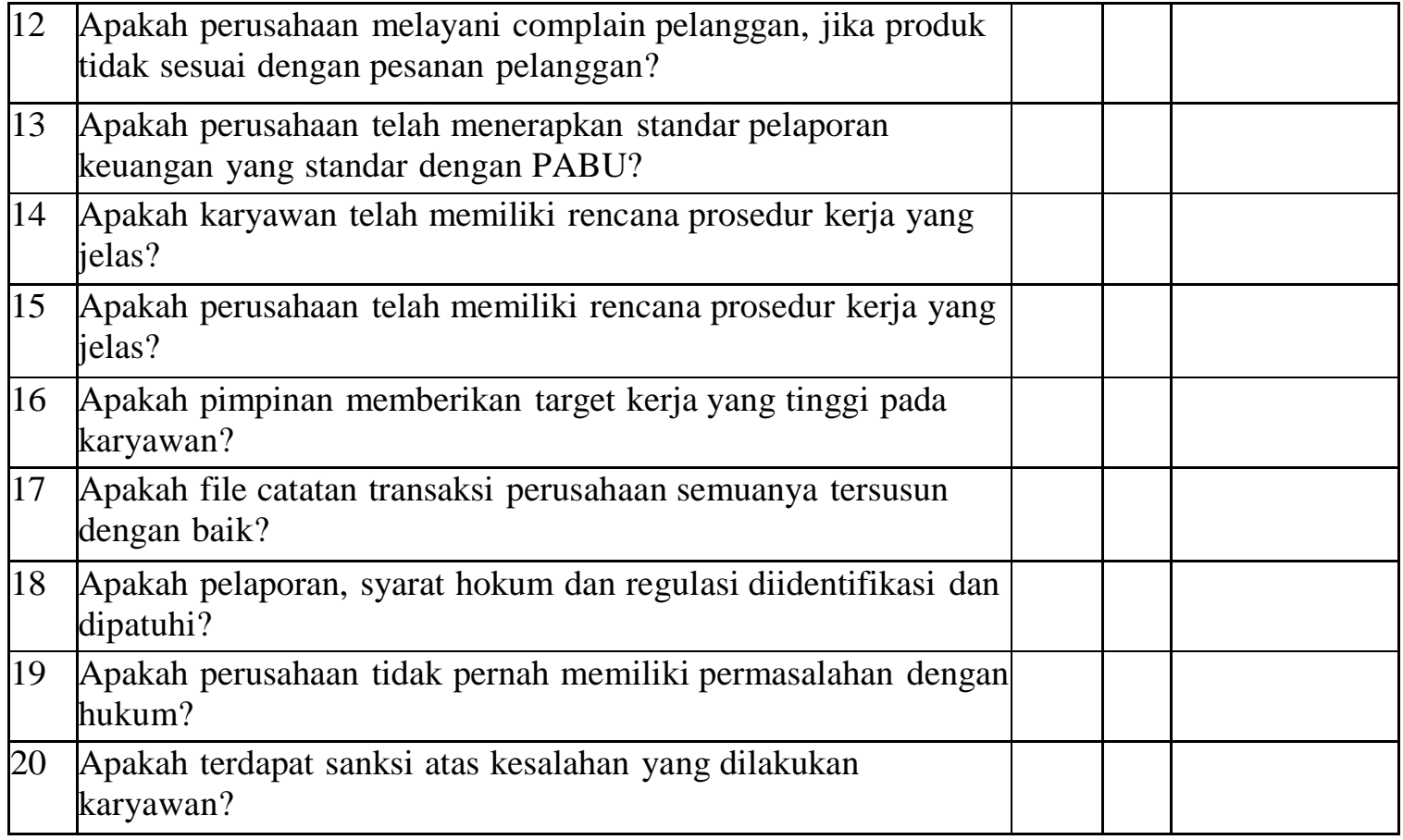

\section{AKTIVITAS PENGENDALIAN}

\begin{tabular}{|c|c|c|c|c|}
\hline \multirow{2}{*}{\multicolumn{2}{|c|}{ PERTANYAAN }} & \multicolumn{3}{|c|}{ YA/ TDK Komentar } \\
\hline & & $\mathbf{Y}$ & $\mathbf{T}$ & \\
\hline 1 & $\begin{array}{l}\text { Apakah perusahaan menyediakan dan mewajibkan karyawan } \\
\text { menggunakan alat pengamanan kerja pada setiap karyawan? }\end{array}$ & & & \\
\hline 2 & $\begin{array}{l}\text { Apakah perusahaan menyediakan alat pemadam kebakaran atau } \\
\text { hydrant untuk mengantisipasi kebakaran? }\end{array}$ & & & \\
\hline 3 & $\begin{array}{l}\text { Apakah sudah ada pengamanan dan pencatatan persediaan } \\
\text { barang masuk dan keluar gudang? }\end{array}$ & & & \\
\hline 4 & $\begin{array}{l}\text { Apakah perusahaan memiliki beberapa pemasok untuk } \\
\text { persediaan bahan baku dan barang furniture? }\end{array}$ & & & \\
\hline 5 & $\begin{array}{l}\text { Apakah perusahaan menyediakan designer untuk mengupdate } \\
\text { barang furniture yang dijual untuk menghindari penjualan } \\
\text { barang kuno? }\end{array}$ & & & \\
\hline 6 & $\begin{array}{l}\text { Apakah perusahaan menyediakan genset untuk mengantisipasi } \\
\text { pemadaman listrik? }\end{array}$ & & & \\
\hline 7 & $\begin{array}{l}\text { Apakah perusahaan melakukan promosi ketika terjadi } \\
\text { penurunan penjualan? }\end{array}$ & & & \\
\hline 8 & $\begin{array}{l}\text { Apakah perusahaan melayani retur penjualan ketika konsumen } \\
\text { complain? }\end{array}$ & & & \\
\hline 9 & $\begin{array}{l}\text { Apakah perusahaan melakukan seleksi konsumen pada } \\
\text { penjualan kredit? }\end{array}$ & & & \\
\hline 10 & $\begin{array}{l}\text { Apakah perusahaan mengecek pengiriman barang dengan sales } \\
\text { order untuk menghindari kesalahan pengiriman? }\end{array}$ & & & \\
\hline 11 & $\begin{array}{l}\text { Apakah dilakukan pemeriksaan pada persediaan yang datang } \\
\text { untuk menghindaripesanan yang tidak dipesan? }\end{array}$ & & & \\
\hline 12 & Apakah setiap transaksi yang terjadi langsung segera dicatat? & & & \\
\hline
\end{tabular}




\section{JAAF (Journal of Applied Accounting and Finance) \\ Volume 2, Number 1, 2018, 85-98}

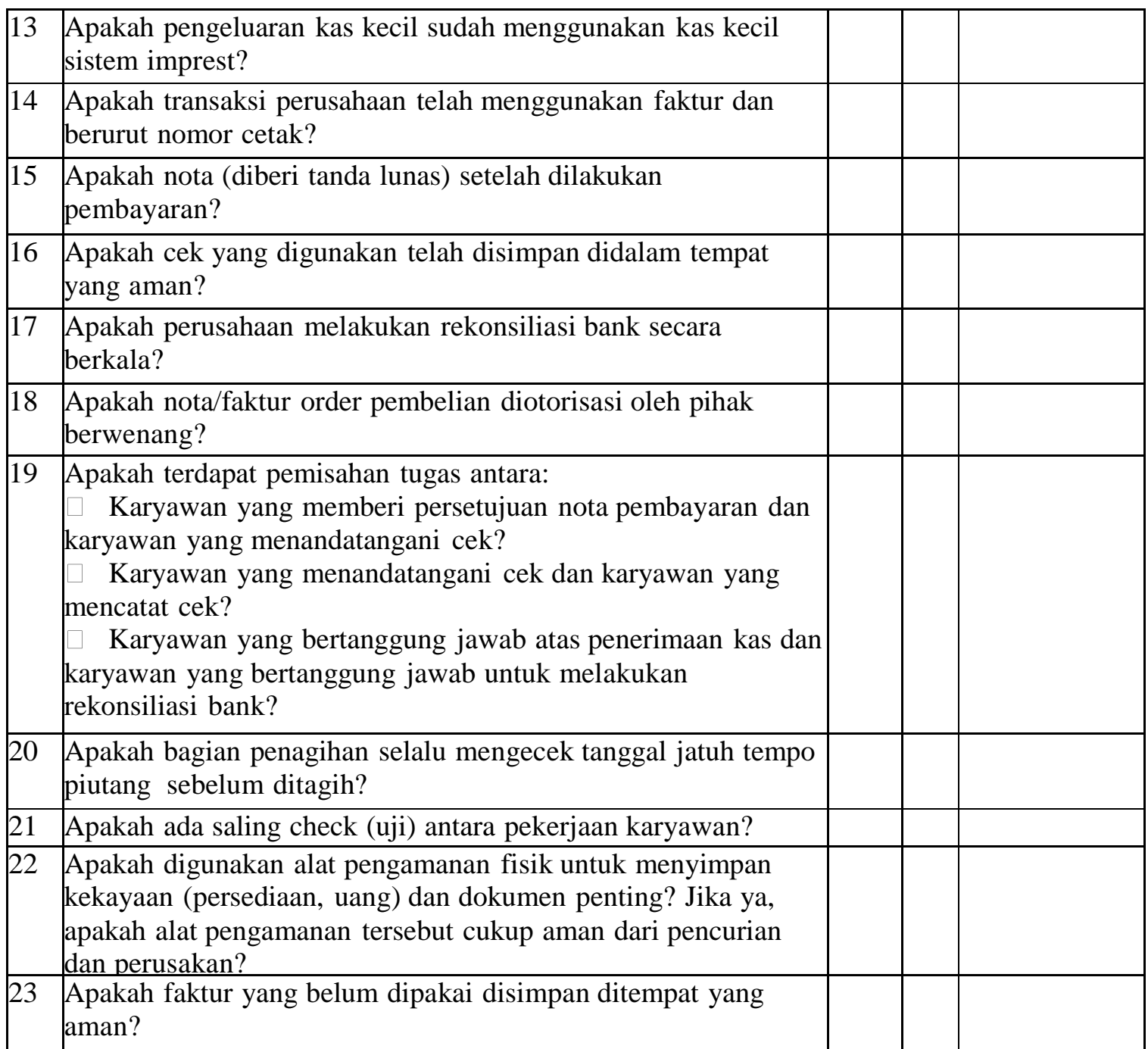

\section{INFORMASI DAN KOMUNIKASI}

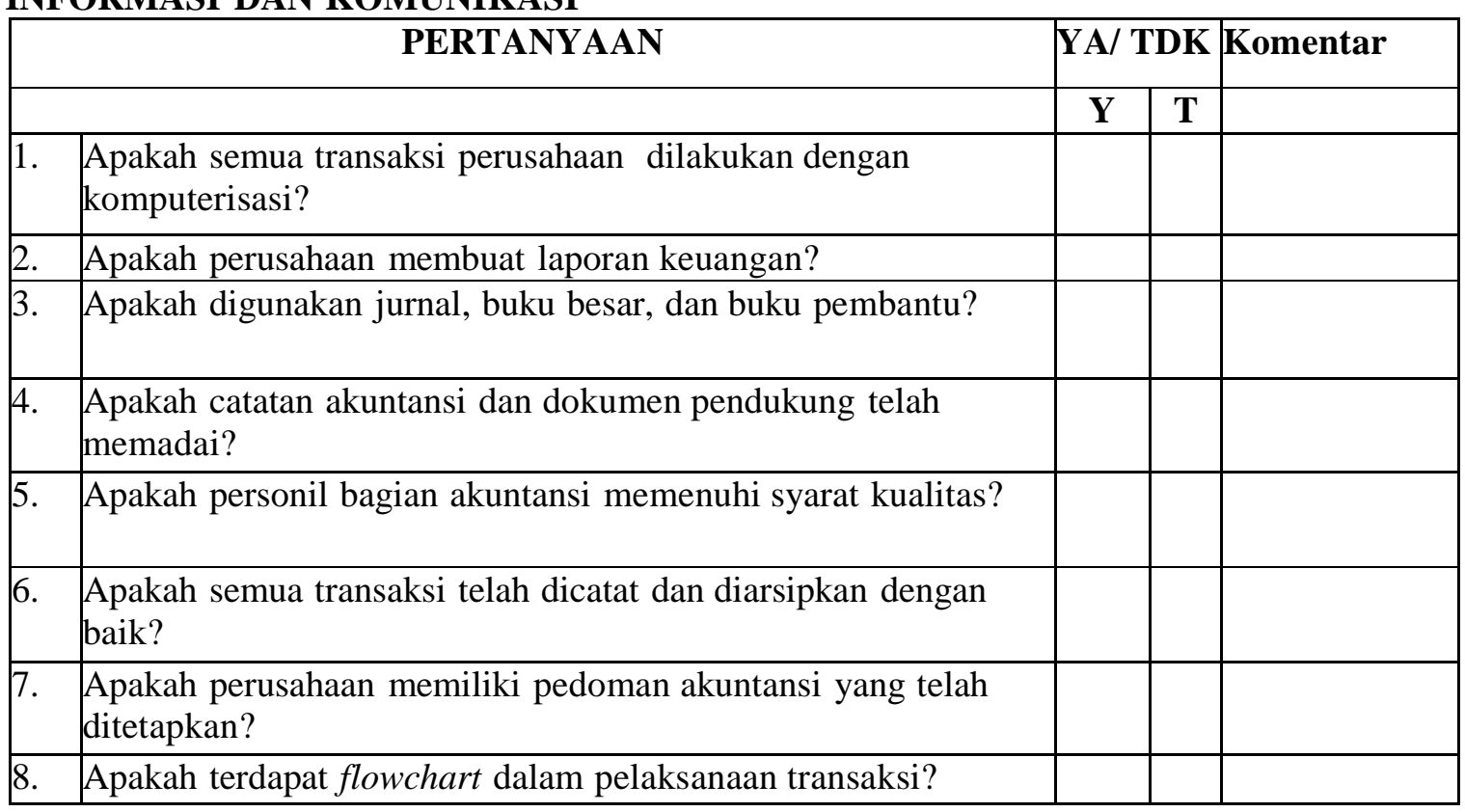




\begin{tabular}{|l|l|l|l|l|}
\hline 9. & $\begin{array}{l}\text { Apakah perusahaan memiliki standar operasional yang tertulis } \\
\text { dan disosialisasikan kepada karyawan? }\end{array}$ & & \\
\hline 10 & $\begin{array}{l}\text { Apakah komunikasi antara karyawan dan pimpinan telah berjalan } \\
\text { dengan baik? }\end{array}$ & & \\
\hline 11 & Apakah ada kegiatan yang mempertemukan & & \\
\hline 12 & Apakah setiap penyimpangan dilaporkan pada & & \\
\hline 13 & Apakah setiap karyawan memahami & & \\
\hline 14 & Apakah pimpinan cukup percaya pada laporan & & \\
\hline
\end{tabular}

\section{PENGAWASAN}

\begin{tabular}{|c|c|c|c|c|}
\hline \multirow{2}{*}{\multicolumn{2}{|c|}{ PERTANYAAN }} & \multicolumn{3}{|c|}{\begin{tabular}{|l|l|} 
YA/TDK & Komentar
\end{tabular}} \\
\hline & & $\mathbf{Y}$ & $\mathbf{T}$ & \\
\hline 1. & Apakah pengawasan dilakukan pada perusahaan? & & & \\
\hline 2. & Apakah perusahaan memiliki dewan pengawas? & & & \\
\hline 3. & $\begin{array}{l}\text { Apakah terdapat fungsi yang tanggung jawabnya serupa dengan } \\
\text { pemeriksa? }\end{array}$ & & & \\
\hline 4. & $\begin{array}{l}\text { Apakah pimpinan mengawasi secara rutin terhadap efektivitas } \\
\text { pengendalian internal? }\end{array}$ & & & \\
\hline 5. & Apakah pengawasan tersebut dilakukan pada saat yang tepat? & & & \\
\hline 6. & Apakah ada modifikasi untuk perubahan kondisi yang terjadi? & & & \\
\hline 7. & Apakah pimpinan cukup terlibat dalam & & & \\
\hline 8. & $\begin{array}{l}\text { Apakah pimpinan rutin melakukan follow up atas kelemahan } \\
\text { berkaitan dengan pengendalian internal? }\end{array}$ & & & \\
\hline 9. & $\begin{array}{l}\text { Apakah pimpinan melakukan pemantauan dan pengukuran } \\
\text { terhadap: produk yang dihasilkan dan peralatan operasional }\end{array}$ & & & \\
\hline 10 & $\begin{array}{l}\text { Apakah pimpinan melaKukan penilaian terhadap kinerja } \\
\text { karyawan? }\end{array}$ & & & \\
\hline 11 & $\begin{array}{l}\text { Apakah pimpinan selalu melakukan pengawasan terhadap arus } \\
\text { masuk dan keluarnya kas perusahaan? }\end{array}$ & & & \\
\hline
\end{tabular}

